\title{
STUDY OF PATTERNS OF PRESENTATION AND MANAGEMENT OF COMPLICATED INGUINAL HERNIAS
}

\section{General Surgery}

\section{Dr. Sarita Durge}

Assistant Professor, Department of General Chandrapur, India.

\section{Dr. Mayur}

Bandawar*

Assistant Professor, Department of General
Surgery, Government Medical College, Surgery, Government Medical College

\section{ABSTRACT}

Background There are a lot of advancement in techniques of elective inguinal hernia surgery, but progress for management of complicated inguinal hernia repair in emergency, fall behind. The aim of study was to know age distribution, pattern of presentation, to evaluate the outcome of various types of surgical procedure done for complicated inguinal hernia and their post-operative complications. Methods and Materials This retrospective study included 62 patients suffering from complicated inguinal hernia, and who underwent emergency surgery, from Jan-2016to Dec2019. Results The mean of age of sampled patients was $53.88+14.23$ years, with increased incidence in males.Right sided, indirect inguinal hernia was frequently involved.Commonest postoperative complication was wound infection. Tension free repair Lichenstein's technique (Hernioplasty) was done in maximum cases. Conclusion Mesh repair (hernioplasty) is acceptable and safe option for inguinal hernia repair in emergency setting. Early hospitalization and timely surgical intervention are associated with better outcome.

\section{KEYWORDS}

Incarcerated, obstructed hernia, strangulated hernia, hernioplasty.

\section{INTRODUCTION}

Inguinal hernia repair is among the most frequent and widespread general surgery procedure performed.

The protrusion of viscus or part of viscus through an abnormal opening in the walls of its containing cavity is called Hernia.75\% of all abdominal wall hernias are found in groin. $95 \%$ groin hernias are inguinal hernias with remaining being femoral hernias.Inguinal hernias are nine times more common in males than female. Inguinal hernia if not treated well timed, presents with complications like, incarceration, strangulation, and bowel obstruction.

Most of the patients with inguinal hernia are asymptomatic in initial phase or having minor discomforts, due to this some patients delay the surgical consultation and present with complicated inguinal hernia.

Hernia is incarcerated (irreducible) when the contents cannot be returned to its original compartment.Hernia is obstructed when the bowel loops present in hernia sac are obstructed. A strangulated hernia is a life-threatening complication, were blood supply to herniating contents is compromised.The complication of hernias(incarceration, strangulation, and bowel obstruction) are found more commonly at extremes of age1.Urgent surgical management is required in patients who presents with incarcerated hernia, incarceration predisposes to obstruction and strangulation and physical examination alone is not diagnostic. Late hospitalization and delayed intervention increase morbidity and mortality.

Inguinal hernia repair is one of the most common operations in general surgery., There are a lot of advancement in techniques of elective inguinal hernia surgery, but progress for management of complicated inguinal hernia fall behind.

The objective of this study was to know the age distribution, identify the pattern of presentation, and to evaluate the outcome of various types of surgical procedure done on complicated inguinal hernia and their post-operative complications

\section{Methods and Materials}

This retrospectivestudy was done in Department of Surgery, Government Medical College,Chandrapur.62adult male patients above 20 years of age, who underwent emergency surgery for complicated inguinal hernia, between Jan 2016to Dec2019 were included in this study. Complicated femoral and other anterior abdominal wall hernia patients, who underwent emergency surgery during same period were excluded.. The cases with spontaneous reduction of inguinal hernia after admission, operated electively were excluded.There was no female patient with complicated inguinal hernia during study period. All patients who underwent elective hernia repair during study period were excluded. Clinical data, including demographic characteristics, clinical findings, surgical procedure details and post-operative complications were collected from medical records. The data collected and tabulated in MS Excel and analyzed using SPSS16. Approval from Institutional Ethics committee has been taken.

\section{Results}

Out of 62 patients in this study,53 (84.48\%) cases had indirect inguinal hernia and $9(14.51 \%)$ cases had direct inguinal hernia.The mean age of patients was $53.88+14.23$ years (30 years was minimum age and 76 years was maximum age). $70.96 \%$ cases presented with right sided hernia and $29.03 \%$ patients had hernia on left side. The commonest content of hernia sac was small bowel loops followed by omentum.

The duration of symptoms ranges from 6-48 hours, represented in Table 1 . Cases which presented after 48 to 72 hours mostly had strangulated hernia and had more post-operative complications.

Table 1: Duration between the onset of symptoms and hospitalization

\begin{tabular}{|c|c|c|}
\hline Duration & No.of cases & Percentage \\
\hline Less than 1 day & 29 & $46.77 \%$ \\
\hline 1-2 days & 7 & $11.29 \%$ \\
\hline 2-3days & 14 & $22.58 \%$ \\
\hline >3days & 12 & $12.90 \%$ \\
\hline
\end{tabular}

Table 2. shows commonest complication was incarceration (Irreducibility)which was present in 28 cases, 22 cases had obstructed hernia and 12 cases had strangulated hernia

Table 2: Type of complicated inguinal hernia and surgical repair done

\begin{tabular}{|c|c|c|c|}
\hline Type of hernia & $\begin{array}{c}\text { Total No. of } \\
\text { patients(n=62) }\end{array}$ & Type of surgery & $\begin{array}{c}\text { No.of } \\
\text { patients }\end{array}$ \\
\hline irreducible & 28 & Hernioplasty & 45 \\
\hline obstructed & 22 & $\begin{array}{c}\text { Omentectomy } \\
\text { +Herniorrhaphy }\end{array}$ & 5 \\
\hline strangulated & 12 & $\begin{array}{c}\text { Bowel Resection, } \\
\text { end to end } \\
\text { anastomosis } \\
\text { +herniorrhaphy }\end{array}$ & 12 \\
\hline
\end{tabular}

The surgical procedure, tension free mesh repair(Lichenstein 's technique) hernioplasty was done in maximum cases $72.58 \%$, this was done in patients with early presentation and with viable hernia sac content.Herniorrhaphy(Bassini's repair)was done in 17 cases 
$(27.41 \%)$, and this was done in cases with non-viable hernia sac contents. Excision of omentum with hernirrahpy was done in 5 cases $(8.06 \%)$.Bowel resection and anastomosis along with tissue repair,herniorrhaphy were performed in 12 cases $(19.35 \%)$ with strangulated inguinal hernia, these were the cases with longer duration of symptoms and delayed hospitalization (Table 2).

Table 3: Postoperative complications and outcome

\begin{tabular}{|c|c|c|}
\hline Complications & Tension free mesh repair & Herniorrhaphy \\
\hline $\begin{array}{c}\text { Hematoma } \\
\text { formation }\end{array}$ & - & 2 \\
\hline Seroma formation & 2 & 1 \\
\hline Wound infection & - & 3 \\
\hline Paralytic ileus & 1 & 4 \\
\hline Neuralgia & - & - \\
\hline Mortality & & 4 \\
\hline
\end{tabular}

Table 3 shows that wound infection was seen in 5 cases managed conservatively, no mesh related infection encountered .Paralytic ileus was there in 4 cases and one patient had chronic pain. Mortality occurred in $6.45 \%$ cases of complicated inguinal hernia patients and this were the cases with delayed presentation to hospital and in this cases contents of hernia sac were non-viable.

In our study it was observed that tension free mesh repair (hernioplasty)was a safe procedure for complicated inguinal hernia patients with viable hernia sac content.

\section{DISCUSSION}

A retrospective study of 62 cases of complicated inguinal hernia was conducted at Department of General Surgery of Government Medical College and hospital Chandrapur,between Jan2016 to Dec 2019.The outcome of the study correlated well with the existing clinical trials.

In our study the mean age is 53.88 years. In study done by PrakashJS et al on groin hernias presenting as surgical emergency, the incidence was highest in the age groups between 60-69 years 2 , whereas in the present study the incidence was highest in 56-65 years age group which correlates with the findings of a study on obstructed hernia by Padmasree G3. Similar studies conducted by Pollock et al and Andrew et al on the outcomes of complicated hernias reported that the mean age of patients with complicated hernias was 55 yrs and 65 yrs respectively, the findings were consistent with the present study.

In our study all patients were male , there was a male preponderance, no single female patient was treated for complicated inguinal hernia during the study period, the findings are consistent with studies of Padmasree G, Tatar et al. ${ }^{3,6}$

The present study reported the incidence of right sided hernias to be about $70.29 \%$ and left sided hernias to be about $29.03 \%$, the findings which had correlation with the studies of Prakash Jet al (right $80 \%$ and left $20 \%$ ) study on groin hernia presenting as surgical emergency. andKulah et al (right versus left: $33,50 \%$ vs $17,40 \%$ ) study conducted on incarcerated inguinal hernias.

In our study $72.58 \%$ of cases were treated by tension free mesh repair (Lichenstein Technique,hernioplasty)and in $27.41 \%$ cases Bassini's repair herniorrhaphy was done, where as $47.16 \%$ of cases in Padmasree G study were treated by hernioplasty and in $28.30 \%$ cases Bassini's repair was done 5 , whereas $75 \%$ of cases in Hariprasad et al's study was treated by herniorrhaphy and no mesh repair was done8. In our study mesh repair was not done in cases with non viable contents of hernia sac to avoid risk of bacterial translocation and wound infection ,where as in study done by Tatar et al and Junji et al mesh was used in cases with strangulated hernia without mesh related complications6,9. According to study of S.S.Bessa et al the use of mesh in repair of incarcerated and strangulated hernia is acceptable,and presence of non-viable intestine cannot be regarded as contraindication for prosthetic repair10.Delayed hospitalization with history of longer duration of irreducibility resulted in gangrenous intestine and needed bowel resection in 12patients in this study, the results of which were comparable with the Eze et al, study on obstructed inguinal hernias.11Postoperative complications are proportional to the duration of complication of inguinal hernia.

The commonest content in hernia sac was small bowel followed by omentum the findings are consistent with study of Amos et al and Goyal et $\mathrm{al}^{12,13}$.

The outcome of this study show that it is not unthoughtful to correct a complicated inguinal hernia with prosthetic material mesh in emergency setting.. Atila et al and Derici $\mathrm{H}$ et al found the same low incidence of wound infections in acute hernia repair with the use of prosthetic mesh in their studies on acute incarcerated hernias.14,15 This also shows similarity with other studies involving the use of prosthetic mesh in complicated hernias. ${ }^{16}$

\section{CONCLUSION}

Tension free mesh repair (hernioplasty)is safe, associated with minimal post-operative complication and having better outcome in complicated inguinal hernia patients with early hospitalization and timely surgical intervention. Proper selection of procedure is important for a patient.

\section{REFERENCES}

1. Maingoat's Abdominal Operations Michael Zinner 11th edition2007:103-121 Prakash JS et al. Int Surg, J 2017 Dec;4(12),3866-3872

Padmasree G. Int Surg J.2019 Jun;6(6);19651971.

4. Pollock R, Nyhus LM. Complications of groin hernia repair. Surg Clin North Am.1983; 63:1363-1.

5. Andrew NJ. Presentation and outcome of strangulated external hernias in a Distric General Hospital. Br Jr Surg. 1981; 68:329-2

6. Tatar et al. Use of Mesh in incarcerated hernia, Balkan Med J, Vol33, No.4.2016.

7. Kulah B, Kulacoglu IH, Oruc MT, Duzgun AP, Moran M, Ozmen MM, et al. Kulah B, Kulacoglu IH, Oruc MT, Duzgun AP, Moran M, Ozmen MM, et al.
Presentation and outcome of incarcerated external hernias in adults. Am J Surg.2001;181(2):101-4

8. Hari PS, Srinivas T. Clinical study on complicated presentations of groin hernias. Int J Res Med Sci. 2017; 5:3303-8.

9. Junji Ueda Surg Today $(2012) 42 ; 359-362$

10. S.S. Bessa et al Use of mesh in management of incarcerated or strangulated hernia, Hernia 2015 Dec, 19(6);909-14

11. Eze JC. MD Enugu, Nigeria. Obstructed Inguinal Hernia: Role of Technical Aid Program. J National Med Assoc. 2004; $96: 6$.

12. Amos R, Koontz MD. Femoral hernia: Operative cases at the John Hopkins Hospital during a twenty-one-year period. AMA Arch Surg. 1952; 64:298-306

13. Goyal S, Shrivastava M, Verma RK, Goyal S. Uncommon Contents of Inguinal Hernial Sac: A Surgical Dilemma. The Indian J Surg. 2015;77(2):305-9.

14. Atila K, Guler S, Inal A, Sokmen S, Karademir S, Bora S. Prosthetic repair of acutely incarcerated groin hernias: a prospective clinical observation cohort study. Langenbecks Arch Suer. 2010; 395:563-8

15. Derici H, Unalp HR, Nazli O, Kamer E, Coskun M, Tansug Tet al. Prosthetic repair of incarcerated inguinal hernias: is it a reliable method? Langenbecks Arch Surg 2010;395(5):575-9.

16. Faridi S. H., etal A study of mesh repair in emergency inguinal hernia surgery. Surg Chron 2016:21(1);17-20 